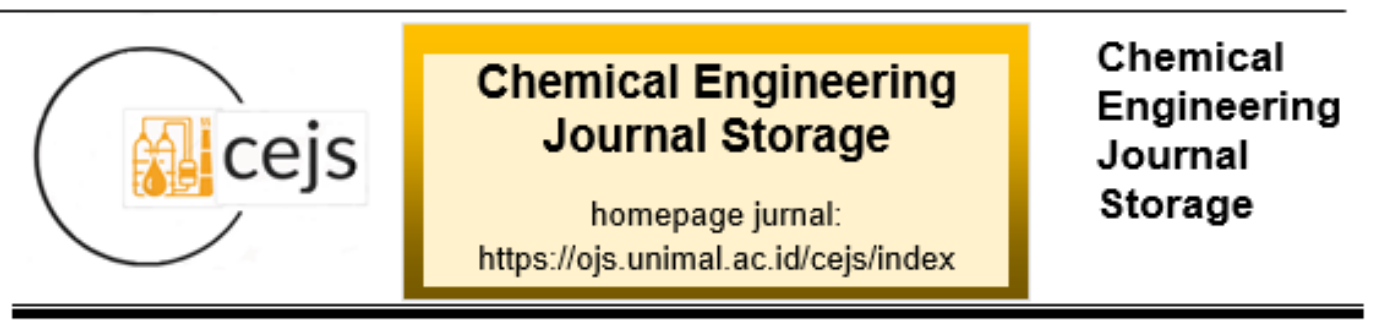

\title{
PEMANFAATAN LIMBAH SERBUK KAYU PADA INDUSTRI KUSEN DI BLANG PULO MENJADI ARANG BRIKET SEBAGAI SUMBER ENERGI ALTERNATIF
}

\author{
Ari Salahudin ${ }^{1}$, Rozanna Dewi ${ }^{1}$, Jalaluddin ${ }^{1}$, Nasrul ZA ${ }^{1}$, Rizka Nurlaila ${ }^{1}$ \\ ${ }^{1}$ Jurusan Teknik Kimia, Fakultas Teknik, Universitas Malikussaleh \\ Kampus Utama Cot Teungku Nie Reuleut, Muara Batu, Aceh Utara - 24355 \\ Korespondensi:HP: 081262315868, e-mail: rozanna.dewi@unimal.ac.id
}

\begin{abstract}
Abstrak
Briket merupakan energi alternatif pengganti bahan bakar yang dihasilkan dari bahan-bahan organik atau biomasa yang kurang termanfaatkan. Beberapa jenis limbah biomasa memiliki potensi yang cukup besar seperti limbah kayu, sekam padi, jerami, ampas tebu, cangkang sawit. Penelitian ini bertujuan untuk memanfaatkan limbah serbuk kayu pada industri kusen agar menjadi barang yang bernilai ekonomis dengan parameter pengujian meliputi analisis kadar air, kadar abu dan nilai kalor. Pembuatan briket ini berbahan baku dari serbuk kayu yang dimulai dari proses pengarangan kemudian ditumbuk dan disaring dengan ukuran ayakan 50 mesh, kemudian dicampur dengan perekat dan dicetak lalu dioven selama 2 jam. Adapun perekat yang digunakan adalah tepung kanji dan air tebu dengan variasi perekat masing-masing $35 \mathrm{ml}, 40 \mathrm{ml}, 45 \mathrm{ml}, 50 \mathrm{ml}$ dan 55 ml. Hasil penelitian menunjukan bahwa beberapa briket sudah memenuhi SNI No.1/6235/2000 briket arang. Hasil terbaik diperoleh pada variasi perekat $45 \mathrm{ml}$ perekat kanji dan air tebu, masing-masing menunjukan kadar air 7,34\% dan 7,76\%, kadar abu 7,542\% dan 7,92\% dan nilai kalor 6.335,651 cal/gr dan 5.477,88 cal/gr. Melihat dari hasil penelitian ini bahwa serbuk kayu dari limbah industri kusen dapat dijadikan salah satu bahan baku alternatif dalam pembuatan briket.
\end{abstract}

Kata kunci: briket, energi alternatif, kadar abu, kadar air, nilai kalor

\section{Pendahuluan}

Briket adalah bahan yang potensial dan dapat diandalkan untuk rumah tangga. Briket mampu menyuplai energi dalam jangka Panjang. Briket didefinisikan sebagai bahan bakar yang berwujud padat dan berasal dari sisa-sisa bahan organtik yang telah mengalami proses pemampatan dengan daya tekan tertentu. Pemanfaatan briket sebagai energi alternatif merupakan langkah yang 
tepat. Briket dapat menggantikan penggunaan kayu bakar yang mulai meningkat konsumsinya dan berpotensi merusak ekologi hutan. Selain itu, harga briket relatif murah dan terjangkau oleh masyarakat, terutama yangn berdomisili di daerah terpencil dan pengusaha briket dapat menyerap tenaga kerja, baik di pabrik briketnya, distributor, industri tungku, dan mesin briket.

Briket umumnya digunakan dirumah makan, hotel, dan dirumah tanggga sebagai bahan bakar terutama untuk aroma khas seperti untuk barbeque, sate, dan lain-lain. Dengan adanya potensi bahan baku yang cukup besar dan semakin berkembangnya sektor industri maka pengembangan industri arang memiliki masa depan yang cerah, serta memungkinkan untuk menghemat devisa dengan menggunakan minyak bumi sebagai bahan bakar. Briket dalam penggunaannya adalah sebagai bahan bakar, berasal dari kayu yang telah dibuat serbuk dan ditambahkan larutan perekat. Selanjutnya, dipress sehingga mempunyai bentuk, ukuran dan kepadatan tertentu dan menjadi produk yang lebih efisien dalam penggunaannya sebagai bahan bakar.

Adapun kualitas briket yang dihasilkan menurut Standar Nasional Indonesia (SNI) dapat dilihat pada tabel berikut :

\begin{tabular}{|c|c|c|}
\hline Parameter & Briket Arang Kayu & Briket Batu Bara \\
\hline Fixed Carbon & $760 \%$ & - \\
\hline Kadar Abu & $15 \%$ & $14 \%$ \\
\hline Nilai Kalor & Minimal $5000 \mathrm{kal} / \mathrm{gr}$ & $5100 \mathrm{kal} / \mathrm{gr}$ \\
\hline Volatile Meter & - & - \\
\hline Kadar Air & Max $8 \%$ & Max $12 \%$ \\
\hline
\end{tabular}

Sumber : Standar Mutu Departemen Energi dan Sumber Daya Mineral, 2008

Dengan penggunaan briket arang sebagai bahan bakar maka kita dapat menghemat penggunaan kayu sebagai hasil utama dari hutan. Selain itu penggunaan briket arang dapat menghemat pengeluaran biaya untuk membeli minyak tanah atau gas elpiji. Dengan memanfaatkan limbah industri kusen sebagai bahan pembuatan briket arang maka akan meningkatkan pemanfaatan limbah hasil hutan sekaligus mengurangi pencemaran udara, karena selama ini 
serbuk kayu yang ada hanya dibakar begitu saja. Manfaat lainnya adalah dapat meningkatkan pendapatan masyarakat bila pembuatan briket arang ini dikelola dengan baik untuk selanjutnya briket arang dijual. Bahan pembuatan briket arang mudah didapatkan disekitar kita berupa serbuk kayu hasil samping industri kusen.

Energi altenatif adalah istilah yang merujuk kepada semua energi yang dapat digunakan yang bertujuan untuk menggantikan bahan bakar konvensional tanpa akibat yang tidak diharapkan dari hal tersebut. Umumnya, istilah ini digunakan untuk mengurangi penggunaan bahan bakar hidrokarbon yang mengakibatkan kerusakan lingkungan akibat emisi karbon dioksida yang tinggi, yang berkontribusi besar terhadap pemanasan global. Biomassa adalah bahan organik yang dihasilkan melalui proses fotosintesis, baik berupa produk maupun buangan (Augusta, 2012). Contoh biomassa antara lain tanaman, pepohonan, rumput, ubi, limbah pertanian dan limbah hutan, tinja dan kotoran ternak. Biomasa adalah semua bahan organik dari tumbuhan tersebut, mulai dari akar, batang, cabang, bunga, buah, biji dan daun. Biomasa yang berupa kayu merupakan sumber energi yang telah dimanfaatkan oleh manusia sejak ribuan tahun yang lalu, dan masih terus dimanfaatkan hingga sekarang, khususnya di daerah pedesaan pada negara yang sedang berkembang.

\section{Bahan dan Metode}

Bahan dan peralatan yang diperlukan dalam penelitian ini antara lain adalah arang dari serbuk kayu, tepung kanji dan air tebu, ayakan mesh ukuran 50, cetakan briket silinder, timbangan digital, stopwatch, cawan porselin, oven, bom calorimeter dan lalin-lain.

Proses pembuatan briket meliputi beberapa tahapan. Tahap pertama yaitu karbonisasi/pirolis serbuk kayu tujuannya yaitu untuk mengkonversi bahan organik menjadi arang. Tahap selanjutnya yaitu arang hasil pirolisa ditumbuk kemudian di mesh dengan ukuran 50 mesh lalu ditimbang 100 gram. Tahap selanjutnya yaitu pencampuran perekat dengan arang sesuai variasi. Selanjutnnya tahap pencetakan briket dan tahap terakhir yaitu analisa kualitas briketProsedur penelitian dapat dilihat pada gambar 1 berikut: 


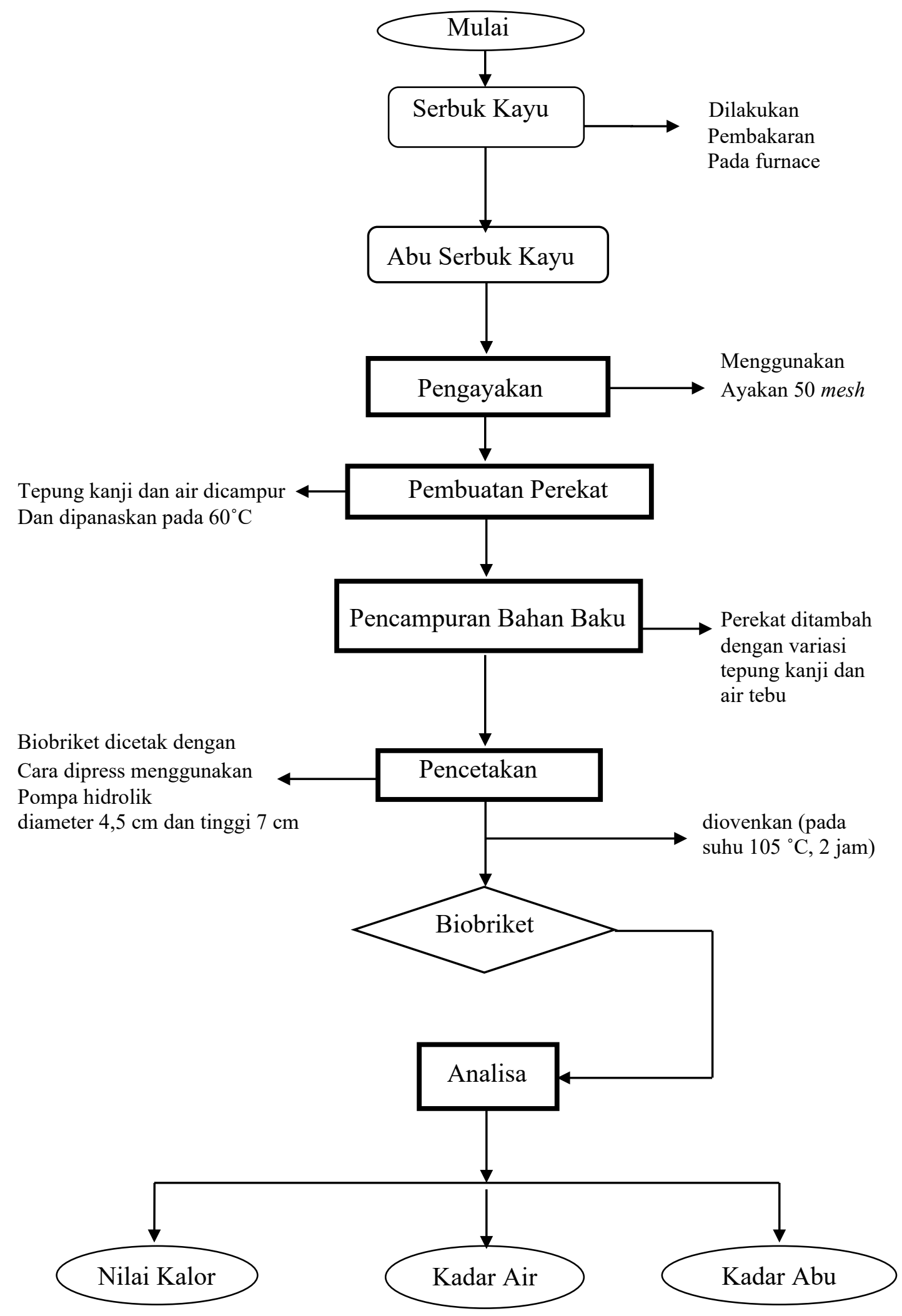

Gambar 1. Proses Pembuatan Briket 
Analisa kadar air dapat dilakukan dengan langkah-langkah berikut :

1. Ditimbang sampel sebanyak 5 gr sebagai berat awal

2. Arang briket tersebut dikeringkan dalam oven selama 2 jam pada temperature $105^{\circ} \mathrm{C}$ sampai beratnya konstan.

3. Arang briket didinginkan dalam desikator dan hasilnya ditimbang sampai berat konstan

4. Hitung kadar air dengan menggunakan rumus :

$\%$ Kadar air $=\frac{\text { Berat awal }- \text { berat akhir }}{\text { Berat awal }} \times 100 \%$

Prosedur Analisa kadar abu yaitu sebagai berikut :

1. Kedalam cawan porselin ditimbang sebanyak 5 gr sampel sebagai berat awal

2. Masukkan arang briket kedalam furnace pada suhu $700^{\circ} \mathrm{C}$ selama 1 jam kemudian didinginkan lalu ditimbang sebagai berat akhir.

3. Dilakukan perhitungan dengan rumus :

Kadar Abu $(\%) \quad=\frac{\text { Berat awal }- \text { berat akhir }}{\text { Berat awal }} \times 100 \%$

Penentuan nilai kalor briket dapat dilakukan dengan menggunakan alat bomb calorimeter, Langkah-langkah kerjanya adalah sebagai berikut :

1. Ditimbang contoh sampel uji briket sebanyak 0,3 gr dan ditimbang kedalam cawan porselin.

2. Disiapkan kawat untuk penyala dengan menggulungnya, kedua ujungnya dihubungkan dengan batang-batang yang terdapat pada bomb dan bagian kawat spiral disentuhkan pada bagian arang yang akan diuji. 
3. Kemudian bom ditutup rapat, bom diisi dengan oksigen perlahan-lahan sampai tekanan 30 bar.

4. Kemudian bom dimasukkan kedalam calorimeter yang telah diisi air sebanyak $1350 \mathrm{ml}$.

5. Kemudian ditutup calorimeter dengan penutupnya.

6. Dihidupkan pengaduk air pendingin selama 5 menit sebelum penyalaan dilakukan, lalu dicatat temperatur air pendingin.

7. Kemudian kawat dinyalakan dengan menekan tombol yang paling kanan

8. Air pendingin terus diaduk selama 5 menit setelah penyalaan berlangsung, kemudian dicatat temperatur akhir pendingin.

9. Dari hasil pengukuran perubahan tempertaur air pendingin, maka nilai kalor dapat dihitung dengan rumus sebagai berikut :

10. Nilai kalor $(\mathrm{kal} / \mathrm{g})=\left(\mathrm{T}_{2}-\mathrm{T}_{1}-0,05\right) \times \mathrm{Cv} \times 0,239 \mathrm{kal}$

(Sumber : Junifa Layla Sihombing, 2006)

Keterangan :

$\mathrm{T}_{2}:$ Temperatur air pendingin setelah penyalaan

$\mathrm{T}_{1}$ : Temperatur air pendingin sebelum penyalaan

$\mathrm{Cv}$ : Panas jenis bomb calorimeter $\left(73529,6 \mathrm{~J} / \mathrm{g}{ }^{\circ} \mathrm{C}\right)$

Kenaikan temperatur akibat kawat penyela $=0,05^{\circ} \mathrm{C}$

$0,239 \mathrm{kal}=1$ joule

\section{Hasil dan Diskusi}

\subsection{Kadar Air dan Kadar Abu} tabel 3.1

Adapun hasil peneliltian kadar air dan kadar abu dapat ditunjukan pada Tabel 3.1 Hasil Analisis Kadar Air dan Kadar Abu

\begin{tabular}{|c|c|c|c|c|}
\hline No & Volume Perekat (mL) & Perekat & $\begin{array}{c}\text { Kadar Air } \\
(\%)\end{array}$ & $\begin{array}{c}\text { Kadar Abu } \\
(\%)\end{array}$ \\
\hline 1 & 35 & \multirow{3}{*}{ Tepung Kanji } & 5,302 & 8,004 \\
\hline 2 & 40 & & 7,25 & 7,946 \\
\hline 3 & 45 & & 7,34 & 7,542 \\
\hline
\end{tabular}




\begin{tabular}{|c|c|c|c|c|}
\hline 4 & 50 & \multirow{5}{*}{} & 7,592 & 7,172 \\
& 55 & & 7,936 & 6,844 \\
\hline 6 & 35 & & 6,368 & 8,926 \\
\hline 7 & 40 & \multirow{4}{*}{ Air Tebu } & 7,344 & 8,342 \\
\hline 8 & 45 & & 7,76 & 7,92 \\
\hline 9 & 50 & & 8,002 & 7,638 \\
\hline 10 & 55 & & 9,342 & 7,48 \\
\hline
\end{tabular}

Kadar air merupakan banyaknya persentase kandungan air yang terdapat dalam suatu bahan. Penentuan kadar air dapat dilakukan dengan beberapa cara, hal ini tergantung pada sifat dari suatu bahan atau zat. Pada umumnya penentuan kadar air dilakukan dengan mengeringkan bahan dalam oven pada suhu 105$110^{\circ} \mathrm{C}$, selama satu jam atau lebih sampai didapat berat konstan.

Abu merupakan bagian yang tersisa dari proses pembakaran yang sudah tidak memiliki unsur karbon lagi. Kadar abu briket diperoleh kandungan abu, silika,bahan baku serbuk dan kadar perekat yang digunakan, salah satu unsur utama penyusun abu adalah silika dan pengaruhnya kurang baik terhadap nilai unsur utama arang yang dihasilkan. Apabila semaki tinggi kadar abu maka semakin rendah kualitas briket karena kadar abu yang tinggi dapat menurunkan nilai kalor briket arang (Afianto,1994).

Hasil penelitian menunjukan perekat tepung kanji dengan volume perekat $35 \mathrm{ml}$ kadar air sebesar 5,302\%, pada $40 \mathrm{ml}$ kadar air sebesar 7,25\%, pada $45 \mathrm{ml}$ kadar air sebesar 7,34\%, pada $50 \mathrm{ml}$ kadar air sebesa 7,592\% dan pada $55 \mathrm{ml}$ sebesar 7,936\% dan kadar abu sebesar $8,004 \%$ pada $35 \mathrm{ml}$ perekat, 7,946\% pada $40 \mathrm{ml}$ perekat, $7,542 \%$ pada $45 \mathrm{ml}$ perekat, $7,172 \%$ pada $50 \mathrm{ml}$ perekat dan $6,844 \%$ pada $55 \mathrm{ml}$ perekat.

Hasil penelitian pembuatan briket perekat air tebu dengan volume perekat $35 \mathrm{ml}$ kadar air sebesar 6,368\%, pada $40 \mathrm{ml}$ kadar air sebesar 7,344\%, pada $45 \mathrm{ml}$ kadar air sebesar 7,76\%, pada $50 \mathrm{ml}$ kadar air sebesa $8,002 \%$ dan pada $55 \mathrm{ml}$ sebesar 9,342\% dan kadar abu sebesar $8,926 \%$ pada $35 \mathrm{ml}$ perekat, 8,342\% pada 
$40 \mathrm{ml}$ perekat, $7,92 \%$ pada $45 \mathrm{ml}$ perekat, $7,638 \%$ pada $50 \mathrm{ml}$ perekat dan $7,48 \%$ pada $55 \mathrm{ml}$ perekat.

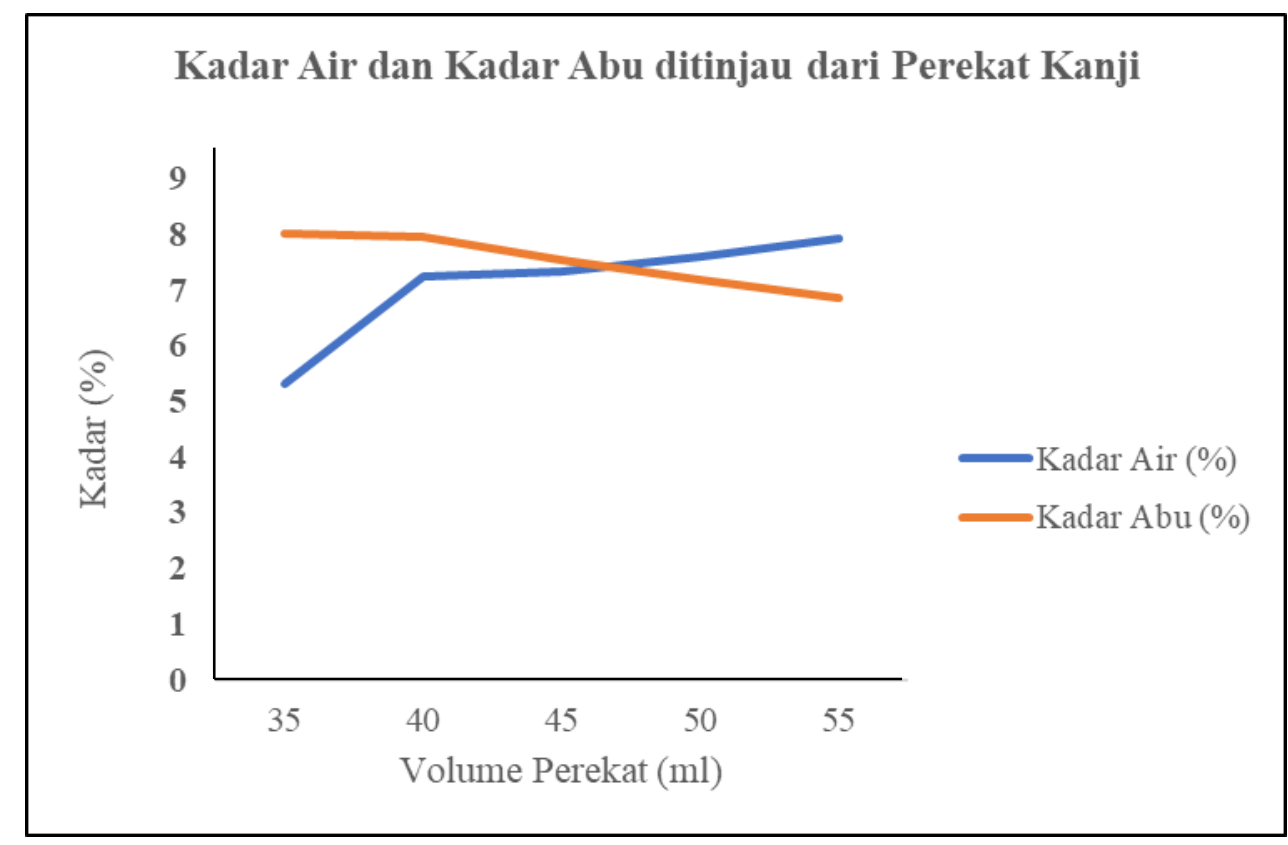

Gambar 2. Grafik kadar air dan kadar abu briket dengan perekat tepung kanji

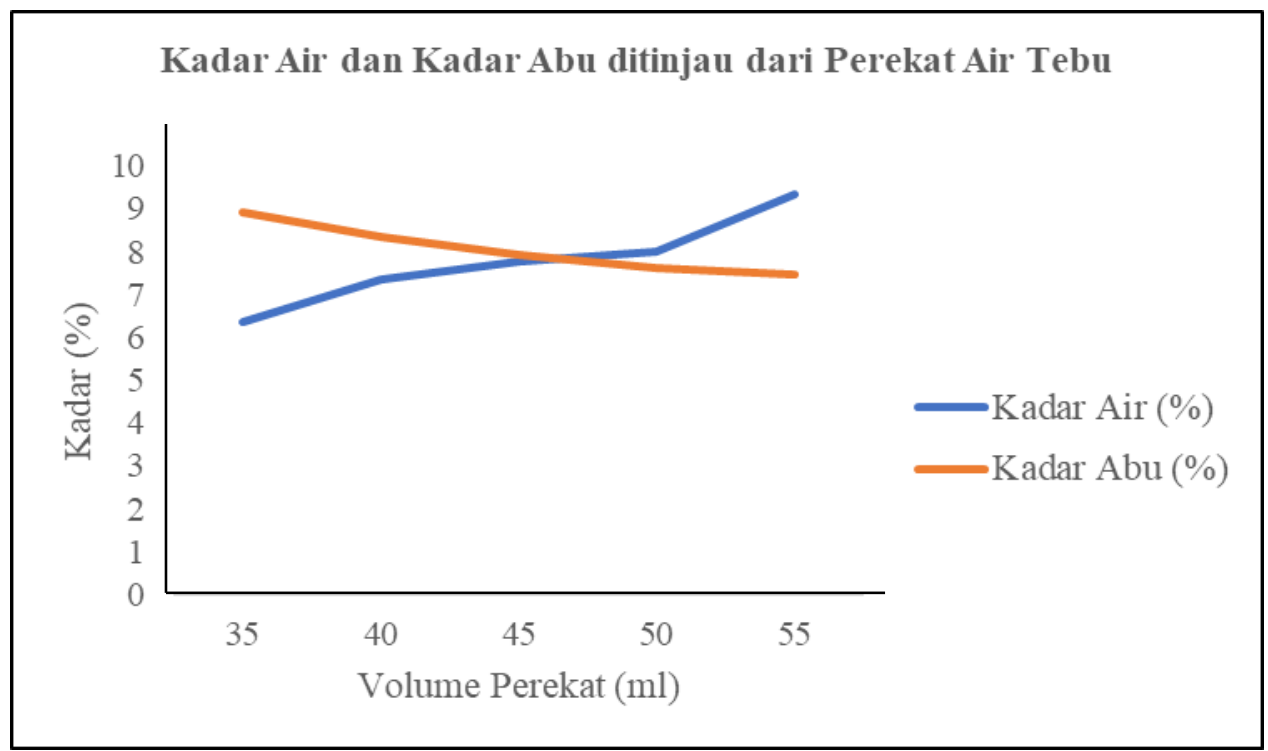

Gambar 3. Grafik kadar air dan kadar abu briket dengan perekat air tebu 


\subsection{Nilai Kalor}

Adapun nilai kalor yang dihasilkan dari perekat tepung kanji dan air tebu dapat dilihat pada Tabel 3.2.

\section{Tabel 3.2 Hasil analisa nilai kalor pada briket}

\begin{tabular}{|c|c|c|c|c|c|c|}
\hline No & $\begin{array}{c}\text { Ukuran } \\
\text { Partikel } \\
(m e s h)\end{array}$ & Spesifikasi & $\begin{array}{c}\text { Berat } \\
\text { arang }(\mathrm{gr})\end{array}$ & $\begin{array}{c}\text { Volume } \\
\text { Perekat } \\
(\mathrm{ml})\end{array}$ & $\begin{array}{c}\text { Nilai } \\
\text { kalor } \\
(\mathrm{J} / \mathrm{g})\end{array}$ & $\begin{array}{c}\text { Nilai } \\
\text { kalor } \\
(\mathrm{cal} / \mathrm{g})\end{array}$ \\
\hline 1 & 50 & $\begin{array}{c}\text { Perekat } \\
\text { tepung } \\
\text { kanji }\end{array}$ & 100 & 45 & 26.509 & $6.335,651$ \\
\hline 2 & 50 & $\begin{array}{c}\text { Perekat } \\
\text { air tebu }\end{array}$ & 100 & 45 & 22.920 & $5.477,88$ \\
\hline
\end{tabular}

Tujuan pengukuran nilai kalor adalah untuk mengetahui nilai panas pembakaran yang dapat dihasilkan briket. Nilai kalor menjadi parameter mutu penting bagi briket sebagai bahan bakar. Semakin tinggi nilai kalor bahan bakar briket, maka akan semakin baik pula kualitasnya. Nilai kalor sangat menentukan kualitas briket arang. Semakin tinggi nilai kalor briket arang semakin baik pula kualitas briket yang dihasilkan. Tingginya nilai kalori briket ini disebabkan karena sampel briket ini berupa serbuk kayu yang banyak mengandung komponen kirnia berupa selulosa, lignin dan semiselulosa sehingga briket ini memiliki kadar karbon terikat yang tinggi. Banyaknya kandungan selulosa yang terdapat dim briket ini meningkatkan nilai karbon terikat dan nilai kalorinya (Goenadi dkk, 2005).

\section{Simpulan dan Saran}

Dari hasil penelitian dapat disimpulkan bahwa:

1. Arang serbuk kayu dapat dimanfaatkan menjadi briket arang. Ukuran partikel (mesh) dan berat perekat sangat mempengaruhi kualitas briket yang dihasilkan. 
2. Kadar air, kadar abu dan nilai kalor briket pada perekat kanji dan air tebu sudah memenuhi standar SNI Briket.

3. Dari hasil uji penelitian yang telah dilakukan dapat disimpulkan briket dengan perekat tepung kanji memiliki kualitas yang lebih baik daripada briket dengan perekat air tebu.

4. Dalam pembuatan briket, moisture briket (kadar air) sangat dipengaruhi oleh perbandingan antara perekat dengan serbuk arang yang digunakan.

Saran pada penelitian ini adalah:

1. Pada saat melakukan pencampuran bahan baku dengan perekat kiranya dapat menggunakan mixer agar hasil pencampuran lebih sempurna dibandingkan dengan pencampuran manual.

2. Pada saat pencetakan briket harus dilakukan dengan hati-hati agar briket tidak patah ataupun rusak.

3. Dalam penelitian kedepan sekiranya para penelitian dapat menganalisa tekanan dan menghitung nilai tekanannya dengan menggunakan alat uji tekan.

\section{Daftar Pustaka}

1. Capah, A. G. (2007). Pengaruh Konsentrasi Perekat dan Ukuran Serbuk Terhadap Kualitas Briket Arang dari limbah Pembalakan Kayu mangium (Acacia mangium Willd). Medan. Departemen Kehutanan. Fakultas Pertanian. Universitas Sumatera Utara.

2. Departemen Kehutanan. Fakultas Pertanian. Universitas Sumatera Utara. Medan.

3. Departemen Energi dan Sumber Daya Mineral (DESDM). (2004). Statistik Energi Indonesia.

4. Departemen Pertanian (Deptan). (2003), Luas Areal dan Produksi Perkebunan Rakyat di Indonesia.

5. Fachry, A. R., Sari, T. I., Dipura, A. Y., \& Najamudin, J. (2010). Teknik Pembuatan Briket Campuran Eceng Gondok dan Batubara sebagai Bahan Bakar Alternatif bagi Masyarakat Pedesaan. Seminar Nasional Perkembangan Riset Dan Teknologi Di Bidang Industri Ke-16, TRTP-52.

6. Hapid, A., Muthmainnah, M., \& Ahmad, A. (2018). Karakteristik Briket Arang Dari Campuran Tempurung Kelapa Dan Serbuk Gergaji Kayu 
Palapi (Heritiera Sp). ForestSains, 15(2), 47-57.

7. Hendra, D., \& Darmawan, S. (2000). Pembuatan briket arang dari serbuk gergajian kayu dengan penambahan tempurung kelapa. Jurnal Penelitian Hasil Hutan, 18(1), 1-9.

8. Iskandar, H, \& Santoso, K. D. (2005). Panduan singkat cara pembuatan arang kayu: alternatif pemanfaatan limbah kayu oleh masyarakat. CIFOR.

9. Iskandar, Haris, Santosa, K. D., Kanninen, M., \& Gunarso, P. (2009). Inisiatif pemanfaatan limbah kayu sebagai sumber penghasilan di tingkat masyarakat. Pengelolaan Sumberdaya Hutan Di Era Desentralisasi, 125.

10. Izzati, K., Mujiburohman, M., Kusmiyati, S. T., Eni Budiyati, S. T., \& Eng, M. (2018). Pemanfaatan Limbah Padat Industri Serbuk Gergaji Kayu Menjadi Briket Sebagai Salah Satu Energi Alternatif. Universitas Muhammadiyah Surakarta.

11. Kadir, A. (1995). Energi: Sumber daya, inovasi, tenaga listrik, dan potensi ekonomi. Penerbit Universitas Indonesia.

12. Malik, U. (2012). Penelitian berbagai jenis kayu limbah pengolahan untuk pemilihan Bahan Baku briket Arang.

13. Masturin, A. (2002). Sifat Fisik dan Kimia Briket Arang dari Campuran Arang Limbah Gergajian Kayu. Skripsi. Fakultas Kehutanan, Institut Pertanian Bogor.

14. Nugraha, J. R. (2013). Karakteristik termal briket arang ampas tebu dengan variasi bahan perekat lumpur lapindo.

15. Pari, G. (2002). Teknologi alternatif pemanfaatan limbah industri pengolahan kayu. Makalah Falsafah Sains. Program Pascasarjana Institut Pertanian Bogor.

16. Putri, R. E., \& Andasuryani, A. (2017). Studi mutu briket arang dengan bahan baku limbah biomassa. Jurnal Teknologi Pertanian Andalas, 21(2), 143-151.

17. Septiani, D. (2012). Pembuatan Biobriket Dari Jerami Padi Dan Tempurung Kelapa Sebagai Energi Alternatif Ramah Lingkungan. Palembang: Politeknik Negeri Sriwijaya.

18. Sheth, P. N., \& Babu, B. V. (2006). Kinetic modeling of the pyrolysis of biomass. Proceedings of National Conference on Environmental Conservation, 453-458.

19. Suryani, A. (1986). Pengaruh tekanan pengempaan dan jenis perekat dalam pembuatan arang briket dari tempurung kelapa sawit (Elais 
Arie Salahuddin / Chemical Engineering Journal Storare $1: 2$ (Oktober 2021) 95-106

quinensis Jacq). Proyek Peningkatan Dan Pengembangan Perguruan Tinggi. Institut Pertanian Bogor, Bogor. 